It follows from all this that the British Glaciological Society, which had the wisdom and enterprise to launch the new fournal of Glaciology, thereby has provided an effective organ for mutual information and interchange of thought to scientists working in a number of interrelated and interdependent fields of research - glaciology, meteorology, climatology, physical geography, geology, pedology, hydrology, oceanography, archaeology, ecology and palaeontology. 'That being true, there is every reason to believe that the fournal of Glaciology is starting upon a highly useful and successful career.

\title{
THE SOCIETY AND THE JOURNAL
}

As a result of the advent of the Fournal of Glaciology and a certain amount of publicity the Society has grown considerably. In November the number of members was 128 ; members and subscribers to the Journal now total about 360 . It is not our purpose to rest at this figure. The size and scope of the Journal depend upon the size of its circulation, from which it follows that this must be further increased. Members will help the Society and increase its usefulness to themselves by making its existence known to any of their friends and colleagues who are likely to be genuinely interested in its work. Particulars and a prospectus will be found on the last page of this issue.

The reception given to the first number of the fournal of Glaciology has been gratifying. Several dozens of letters have been received and it is clear that it fills a real want. Appreciations have been sent from Switzerland, the United States of America, Canada, Sweden, Norway, France, Belgium, Poland, Czechoslovakia, Eire and several other countries.

It is satisfactory to the Committee and to the Editorial Committee that the Fournal of Glaciology has been launched and appreciated.

\section{GLACIER RESEARCH}

\section{THE GLACIER PHYSICS COMMITTEE}

GLACIOLOGY has now reached a stage when mere observation in the field is no longer an adequate method of attack for the problems which are still unsolved. Experimental research on the fundamental physical and mechanical properties of ice is urgently required before a quantitative theory of glacier flow, based upon modern concepts of plasticity in crystalline solids, can be formulated. For testing such theories in the field, novel methods of research will be needed for measuring flow rates and stresses in the interior of glaciers at considerable depths.

It is clear that the development of research on lines such as these will only be possible with the co-operation of experts in several fields. With this purpose in view a Glacier Physics Committee has been formed on the initiative of Dr. M. F. Perutz and under the chairmanship of Mr. G. Seligman. The following have agreed to serve on it:

Dr. F. P. Bowden (Friction of solids).

Dr. E. C. Bullard, F.R.S. (Geophysics).

Mr. Vaughan Lewis (Geomorphology). 
Professor A. Austin Miller (Geology, Geography) representing the Royal Geographical Society.

Dr. E. Orowan, F.R.S. (Plasticity).

Dr. M. F. Perutz (Crystallography), Honorary Secretary.

Sir Geoffrey Taylor, F.R.S. (Applied mechanics).

Mr. J. M. Wordie (Polar exploration, glaciology).

The opinion was held that the Committee should be composed mainly of residents in Cambridge in order to facilitate formal and informal meetings. This arrangement has proved satisfactory and since the first meeting much useful preliminary work has been accomplished.

The first meeting to decide on methods and on general lines of procedure was held on November 8, 1946 .

The discussion centred first on suitable methods for determining the creep properties of ice and of measuring flow rates and stresses in the interior of glaciers. Sir Geoffrey Taylor and Dr. Orowan expressed the opinion that the hydrodynamic treatment of glaciers as a flowing mass of constant viscosity, which had been customary in the past, was an inadequate approximation and was not in accord with modern knowledge of the behaviour of polycrystalline masses undergoing plastic deformation. They considered it essential to measure the yield stress and the creep rates of ice under conditions similar to those prevailing in a glacier. Dr. Perutz thought that such research should be closely linked with microscopic studies of crystal growth and re-orientation under strain. The Committee recommended that researches on these lines should be undertaken at the Cavendish Laboratory under the general direction of Dr. Orowan and Dr. Perutz, provided sanction to carry out this work could be obtained.

In order to measure flow rates and stresses in the interior of glaciers it will be necessary to devise an efficient method of drilling holes in glaciers. Dr. Bullard suggested various techniques which might be tried. Dr. Orowan mentioned new types of strain gauges which might be used for measuring the stresses at the bottom of bore-holes. It was suggested that flow rates in the interior of glaciers might be measured with the help of timed detonators which could be placed in bore-holes at determined positions in the glacier. Explosion could take place some weeks or months later and the position of the detonators at the time of explosion could be determined seismographically. The Committee recommended that these methods should be developed under the general direction of Dr. Bullard.

The Committee was anxious that glaciological research in the Polar regions should be revived and suggested that this might conveniently be done in connection with the Falkland Islands Dependencies Survey, if facilities to carry this out were granted. It was felt that only a long-term scheme would yield scientific results of any value, because it would be necessary, before any serious research could be begun, to make a preliminary survey of the problems that needed investigation and of the localities where such investigations could conveniently be carried out. The Committee recommended that the Secretary should approach the Colonial Office to see if it were possible to secure the appointment of a glaciologist within the framework of the Falkland Islands Dependencies Survey for a period of five years. It was thought that there would be no very great difficulty in finding a young student willing to train for this work. 
In order to guide the Committee in formulating a detailed programme and in devising suitable methods of research, Dr. Perutz has written a report summarizing the present state of the problems of Glacier Physics. This summary is published below.

\title{
REPORT ON PROBLEMS RELATING TO THE FLOW OF GLA C I E R S
}

\author{
By M. F. Perutz (Cambridge)
}

\section{Viscous Flow : Experiments and Theory}

The great naturalists of the nineteenth century discovered glacier flow and described its main features. They showed that the flow properties of glaciers resemble those of highly viscous fluids, and attributed the ductility of the apparently brittle substance ice to the effects of regelation or to the relative motion of individual ice crystals.

Accurate measurements of glacier flow were begun in the Alps in the I890's and continued for several decades. ${ }^{1}$ Surface velocities were measured at many points on glacier tongues, bore-holes reaching down to the rock bed were drilled and their progression was carefully recorded. Finally, in the I930's, reliable and less tiresome methods of measuring glacier depths became possible with the introduction of seismic soundings.

Many of the experiments and observations were accompanied by attempts at theoretical interpretation. One of the earliest of these was Finsterwalder's geometric streamline theory, ${ }^{2}$ which correlated accumulation and ablation with glacier flow and explained the periodic advance and recession of glaciers. Finsterwalder's theory is mainly descriptive and free from all arbitrary assumptions; on the other hand, this makes the theory so general that it is difficult to derive from it any quantitative predictions. Hess actually employed it to obtain equations for the total mechanical energy of a glacier, involving integration over six dependent variables which cannot be evaluated without a host of dubious assumptions. The solutions of these equations led him to some exceedingly improbable conclusions concerning the stress distribution in glaciers. More important are Weinberg's and Somigliana's attempts to formulate a quantitative theory of glacier flow on a hydrodynamic basis. 3,4 Somigliana treats the stationary flow of a viscous liquid in an evenly inclined cylindrical channel under the influence of gravity. His work is outstanding for the clear exposition of the underlying assumptions and important because it leads to a relation between the depth and surface velocity of a glacier. Lagally extended his theory and used it to derive the average viscosity of glacier ice from the change in flow velocity between the edges and the centre of a glacier surface ${ }^{5}$; he obtained a value of $\mu=\mathrm{I} \times \mathrm{Io}^{14} \mathrm{~g} . \mathrm{cm}^{-1} \mathrm{sec}^{-1}$. Taking the cross-section of the glacier bed to be a semi-ellipse whose major axis is very large compared to the minor one, and the velocity of flow on the rock bed to be negligibly small, he obtains the equation

$$
z=\sqrt{\frac{2 \mu \mathrm{V}_{0}}{\rho g \sin \alpha}}
$$

where $z$ is the depth of the glacier, $\mu$ the viscosity of ice, $V_{0}$ the surface velocity at the centre of the glacier, $\rho$ the density of ice, $g$ the acceleration of gravity and $\alpha$ the inclination of the 